\title{
Research Paper: Immediate Effect of Textured Insole on Static Balance in Individuals With Flexible Flatfoot
}

\author{
Aliakbar Nazari', Behnam Hajiaghaei', Javad Alaee', Behshid Farahmand ${ }^{1 *}$
}

1. MSc., Department of Orthotics and Prosthetics, School of Rehabilitation Sciences, Iran University of Medical Sciences, Tehran, Iran.

$\begin{gathered}\text { Use your device to scan } \\ \text { and read the artice online }\end{gathered}$
als With Flexible Flatfoot. Journal of Modern Rehabilitation. 2016; 10(4):163-168. https://doi.org/10.18869/nirp.jmr.10.4.163
doi: ${ }^{\circ}$ https://doi.org/10.18869/nirp.jmr.10.4.163

Article info:

Received: 16 May. 2016

Revised: 13 Jun. 2016

Accepted: 11 Aug. 2016
Keywords:

Static balance, Flexible flatfoot, Textured insole

\begin{abstract}
Introduction: Flatfoot is a common orthopedic disorder in the world. Some investigations have demonstrated flatfoot as the cause of many problems such as balance impairment by affecting the proprioception of the soles. Balance reduction can lead to injuries too. In this regard, textured surfaces can be used for stimulating somatosensory system as well as improving proprioception. Therefore, this study aimed to examine the role of textured insole on somatosensory system stimulation and consequently its effect on the balance improvement in individuals with flatfooted.
\end{abstract}

Material and Methods: This study is a kind of interventional quasi-experimental research. Twenty male students of Iran University of Medical Sciences (Mean [SD] age 22.1 [1.3] years with bilateral flexible flatfoot) were recruited in this study by convenience sampling method. The study variables were as follows: anteroposterior and mediolateral displacements and total velocity of the center of pressure that were measured using a Kistler force plate instrument. Repeated measures ANOVA test was used to compare the test values.

Results: Textured insole reduced the average of all measured parameters in eyes closed condition. This reduction was significant in both anteroposterior displacement and total velocity parameters $(\mathrm{P}<0.05)$. Surprisingly, the common arched medical insole leads to balance reduction when used in shoe.

Conclusion: Data analysis demonstrated that using textured insoles can be effective in balance improvement in individuals with flexible flatfooted. This can be the result of extroception and proprioception improvement. On the other hand, we found that common traditional insoles can disturb balance in this group of patients.

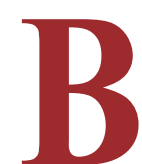

\section{Introduction}

alance is the ability to maintain body's center of gravity within the base of support
[1]. Maintaining balance depends on receiving accurate information from visual, vestibular, and somatosen-sory systems [2-7]. Somatosensory system consists of a series of superficial and deep mechanoreceptors [2]. While

* Corresponding Author:

Behshid Farahmand, MSc.

Address: Department of Orthotics and Prosthetics, School of Rehabilitation Sciences, Iran University of Medical Sciences, Tehran, Iran. Tel: +98 (21) 22228051

E-mail:farahmandb1@yahoo.com 
standing or walking, the data of superficial and deep receptors of the foot combine with each other to improve balance [8]. Recent studies have shown that flatfoot can affect this balance [9-18].

Some studies noted that flatfoot can be considered a factor in reducing balance by disturbing the neuromechanical link of kinetic chain [15]. In a study by Harrison performed on partici-pants with the average age of 18 years, it was found that the flatfoot has a direct relationship with reduced postural stability [12]. In Cobb study, 32 subjects with the mean age of 29 years were examined. The results indicated that subtalar joint pronation was effective in reducing balance in the subjects. This reduction may happen as a result of the foot structure loosening [11]. Akbari et al. reported that this reduced balance in these patients is due to the change in foot orientation that ultimately leads to dysfunction of mechanical receptors [9].

Nowadays, several surgical and conservative methods are used to treat or reduce symptoms of foot disorders. Foot orthoses is widely applied as a non-invasive treatment [19]. Medical insole is an example of such orthoses. Recently, the textured insoles have also been considered in improvement of sensation status of plantar surface [20] or ankle injuries [21]. The use of textured insoles is based on the assumption that it changes the discharge rate of the mechanical receptors [19, 22, 23]. In addition, based on the theory of sensory reweighting, enhancement of sending data via mechanoreceptors may somewhat offset the inadequacy of other sources of balance $[21,24,25]$. Aruin and colleagues found that textured insoles could be used to improve the symmetry of gait in healthy young subjects [26]. Another study by Palluel, performed on 19 elderly people and 19 healthy young people, assumed that spike insole had the ability to stimu-late the proprioceptors. The results of his study indicated that the use of these insoles would be useful in improving balance parameters, especially in younger people [27]. Waddington found that putting textured in- sole inside shoes could enhance perception of the ankle position in athletes and improve balance [28]

However, proper research is not available about the effect of orthoses on somatosensory system and their role in improving the balance of people with flexible flatfoot. Therefore, this study aimed to determine whether textured insole was a convenient and efficient intervention for improving balance ability in this people.

\section{Materials and Methods}

This is a quasi-experimental study with intervention. A total of 20 males with a mean (SD) age of 22.1(1.3) years and the average height of 178(9.6) cm with bilateral flexible flatfoot were recruited in this study using simple nonrandom sampling. Demographic characteristics of participants are presented in Table 1. The participants who had flatfoot were enrolled in the study based on the foot posture index. Validity and reliability of this index has already been approved [29]. Based on this criteria that evaluates foot on all three planes with scoring range from -12 to +12 , subjects who scored $\geq+6$ were initially entered into the study. This scoring system consists of six items that each of them can be scored from -2 to +2 . Finally, sum of these items will be the total score. Then each participant was asked to stand on his toes. Forming the arch at the plantar surface was an indicator of flexible flatfoot. Exclusion criteria were as follows: history of any orthopedic or neurological injury, history of damage to the vestibular system or brain, visual impairment, using drugs affecting the balance, use of orthosis within 6 months before the test, doing professional sports, inability to perform the tests due to any physical problems and unwillingness to cooperate until the end of the test for any reason.

After completing the consent form by participants, insoles and proper footwear for each of them were prepared. This research was approved by the Ethics Committee of Iran University of Medical Sciences. Two types of in-

Table 1. Demographic characteristics of the participants

\begin{tabular}{ccc}
\hline & Mean \pm SD & Range \\
\hline Age $(\mathrm{y})$ & $22.1 \pm 1.3$ & $20-26$ \\
Weight $(\mathrm{kg})$ & $72.7 \pm 8.5$ & $59-94$ \\
Height $(\mathrm{cm})$ & $178.0 \pm 9.6$ & 190 \\
Body mass index score $\left(\mathrm{kg} / \mathrm{m}^{2}\right)$ & $22.6 \pm 2.1$ & $18-29$ \\
Foot posture index score & $8.5 \pm 1.4$ & $6-10$ \\
\hline
\end{tabular}


soles used in this study were common insoles available in the market and the technical orthopedic dep. of the Iran University of Medical Sciences (these insoles is made of Ethylene-Vinyl Acetate [EVA] and consists of a mediallongitudinal arch support and a heel cup), and textured insole (these insoles were prepared in the aforementioned department, based on the foot size of the participants). Specifications of textured insoles were as follows: overall thickness of the insole was $5 \mathrm{~mm}$; small nubs with the diameter of $5 \mathrm{~mm}$, nubs height as $3 \mathrm{~mm}$ and the distance between nubs was $4 \mathrm{~mm}$. In addition, the density of EVA insole was $320 \mathrm{mg} / \mathrm{cm} 3$ and its shore was 45 (Figure 1).

A Kistler force plate with dimensions of $50 \times 60 \mathrm{~cm}$ was used in this study. Device filtering frequency for passing the data was set on $10 \mathrm{~Hz}$ and sampling frequency was set on $100 \mathrm{~Hz}$. The study was performed in the aforesaid department. All participants were asked to use shoes and insoles and walk for 5 minutes. Then they were asked to stand with eyes closed on the force plate. It results in elimination of the visual impact to obtain more refined effect from mechanoreceptors stimulation. The distance between ankles while standing, was determined as two third of the distance between subject's anterior superior iliac spines. External rotation of lower extremity depends on the comfort level of the participant [30]. Required time for each test was 30 seconds [15]. Performing tests included standing on the force plate 1) with shoes alone, 2) with shoes and common insole, and 3 ) shoes and textured insole. Each trial was repeated 3 times. Data were analyzed using Excel (2013) and SPSS (version 21) software.

As the normal distribution of data was confirmed by Shapiro-Wilk test, the parametric repeated measures ANOVA was conducted. Then, the least significant difference (LSD) was used to determine the difference between tests. The $\mathrm{P}$ value less than 0.05 was considered statistically significant. The average value of the measured indices and the results of post hoc test are present-

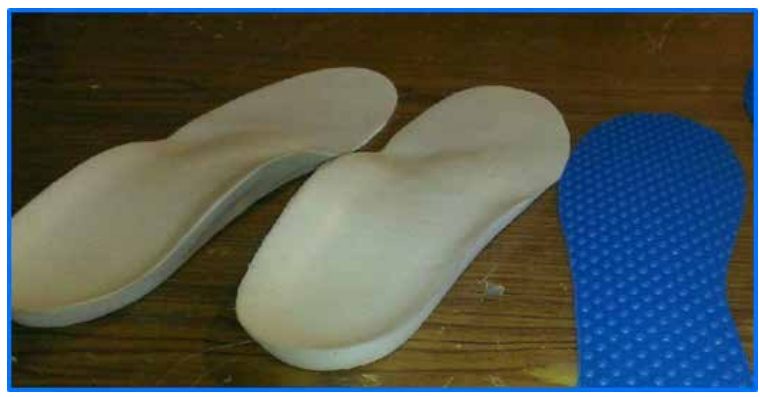

$J \mathrm{MR}$

Figure 1. Textured insole (right) and common insole (left) used in this study ed in Tables 2 and 3, respectively. To calculate the force plate data, the following formulae were used:

$$
\begin{aligned}
& \text { First:Displacement } \text { (anteroposterior) }: \sum_{(n=1)}^{(n=1)} \sqrt{\left(X_{i}-X_{i-1}\right)^{2}}
\end{aligned}
$$

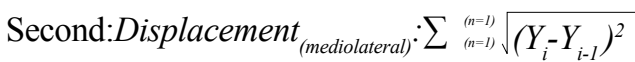

$$
\begin{aligned}
& \text { Third:Velocity }{ }_{\text {(total) }}: \frac{\sqrt{\left(\sum_{(n-I)}^{(n=I)} \sqrt{\left(X_{i}-X_{i-1}\right)^{2}}\right)^{2}+\left(\sum_{(n-I)}^{(n=I)} \sqrt{\left(Y_{i}-Y_{i-1}\right)^{2}}\right)^{2}}}{t}
\end{aligned}
$$

$X$ : anteroposterior displacement of CoP; $Y$ : mediolateral displacement of CoP; and $T$ : time of standing on the force plate.

\section{Results}

The anteroposterior (AP) displacement of the center of pressure $(\mathrm{CoP})$ showed a significant difference between the common insole and textured insole (Sig. $=0.017$, $\mathrm{P}<0.05$ ). Mediolateral (ML) displacement of the $\mathrm{CoP}$ for textured insole was lower than other intervention but the difference was not statistically significant $(\mathrm{P}>0.05)$. The total velocity also indicated a significant difference between common insole and textured insole ( $\mathrm{Sig} .=0.01$, $\mathrm{P}<0.05)$ as well as the common insole versus shoes alone (Sig. $=0.024, \mathrm{P}<0.05)$ (Figure 2). Although differences in balance indices value among aforementioned states were considerable, the difference between the textured insole and shoes was not statistically significant. The results are presented in Tables 2 and 3.

\section{Discussion}

According to the previous studies, flatfoot affects static stability. Unfortunately, there is no research on the impact of foot orthoses on the somatosensory system performance in people with flexible flatfoot. Therefore, this study aimed to evaluate whether the stimulation of mechanoreceptors of plantar surface would have a significant impact on patients' balance. The results of this study showed that use of textured insole can be effective in increasing the stability of individuals with flexible flatfoot. Moreover, the results indicated that the embedding common arch support in the shoes decreases the stability of participants. This might demonstrate some facts. First, it is possible that the damaging effects of the change in foot's natural orientation, and subsequently unbalanced and abnormal weight distribution in plantar surface results in exerting inappropriate pressure and tensions to soft tissue. As a result, the optimal performance of the somatosensory system in this area is likely to be affected. These changes may undermine perception of nerve signals transmitted from the plantar surface 
Table 2. Values of balance parameters in different condition

\begin{tabular}{cccc}
\hline & Textured Insole & Common Insole & Shoe \\
\hline Anteroposterior displacement $(\mathrm{mm})$ & $230.3 \pm 841.9$ & $307.2 \pm 1064.4$ & $217.6 \pm 958.4$ \\
Mediolateral displacement $(\mathrm{mm})$ & $68.1 \pm 470.6$ & $179.8 \pm 535.5$ & $137.1 \pm 477.9$ \\
Total velocity $(\mathrm{mm} / \mathrm{min})$ & $522.4 \pm 1929.1$ & $526.3 \pm 2383.0$ & $468.5 \pm 2141.8$ \\
\hline
\end{tabular}

Table 3. LSD post hoc results ( ${ }^{*}$ means significant difference)

\begin{tabular}{|c|c|c|c|}
\hline & Tests Comparisons & Means Differences & Significance \\
\hline \multirow{3}{*}{$\begin{array}{l}\text { Anteroposterior dis- } \\
\text { placement }(\mathrm{mm})\end{array}$} & Shoe-common insole & -105.98 & 0.073 \\
\hline & Shoe-textured insole & 116.54 & 0.113 \\
\hline & Textured insole-common insole & 222.53 & $0.017^{*}$ \\
\hline \multirow{3}{*}{$\begin{array}{l}\text { Mediolateral displace- } \\
\text { ment }(\mathrm{mm})\end{array}$} & Shoe-common insole & -56.51 & 0.072 \\
\hline & Shoe-textured insole & 5.26 & 0.755 \\
\hline & Textured insole-common insole & 61.71 & 0.112 \\
\hline \multirow{3}{*}{$\begin{array}{l}\text { Total velocity } \\
(\mathrm{mm} / \mathrm{min})\end{array}$} & Shoe-common insole & -242.00 & $0.024^{*}$ \\
\hline & Shoe-textured insole & 212.07 & 0.067 \\
\hline & Textured insole-common insole & 454.07 & $0.010^{*}$ \\
\hline
\end{tabular}

$J \mathrm{MR}$

to the central nervous system. Second, the stimulation of somatosensory system by textured insoles can reduce this distortions and create better perception about the foot posture on the underside [20].

In this respect, the present study is in line with the results of Steinberg [31] and Palluel [27] studies. These researchers believe that textured insole is effective in better perception of the foot posture in young people. It should also be noted that based on our study, the restora- tion of natural foot orientation does not necessarily improve balance. Because according to our find-ings, using conventional arch support impairs the balance. This poor balance may result from the change in foot posture that a person got used to it over the years. These findings are incon-sistent with the results of Satvati [16] and Takada [17] studies. Finally, this study was about the immediate effect of aforementioned insoles. The long-term use of such insoles might lead to different results. Hence, this could provide the basis for future research. These insoles

\section{- Shoe Common insole Textured insole}

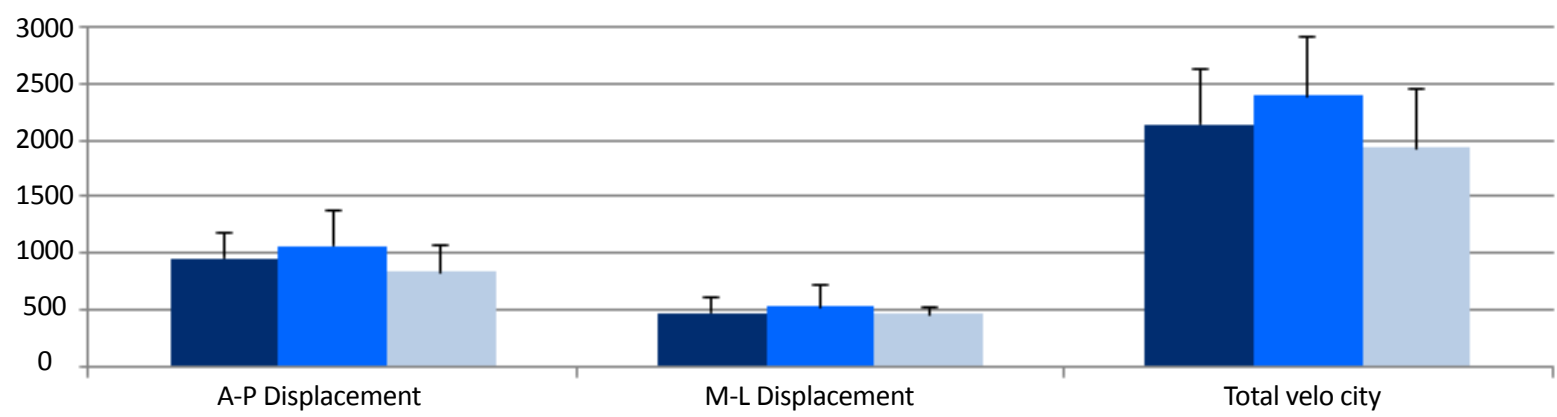

Figure 2. Comparing the tests between conditions 
can also be tested in people with weak eyesight and even blind people who rely more on other sources of balance.

In conclusion, the results of this study suggest that textured insole has the ability to significantly increase the balance. Thus, as a low-cost, accessible and non-invasive intervention, use of such insoles is recommended to people with flexible flatfoot.

\section{Acknowledgements}

This paper is extracted from Mr. Nazari MSc. thesis, Department of Orthotics and Prosthetics, School of Rehabilitation Sciences, Iran University of Medical Sciences, with the title "The mediate effect of textured insole with medial arch support on static balance in individual with flexible flat foot". Iran University of Medical Science, School of Rehabilitation, covered financial costs of the project. The authors would like to thank the department officials, as well as Dr. Jalali, head of the center. Also the authors highly appreciate all participants for contribution in this research.

\section{Conflict of Interest}

The authors declared no conflicts of interest.

\section{References}

[1] Cote KP, Brunet II ME, Gansneder BM, Shultz SJ. Effects of pronated and supinated foot postures on static and dynamic postural stability. Journal of Athletic Training. 2005; 40(1):4146. PMCID: PMC1088344

[2] Christovão TCL, Neto HP, Grecco LAC, Ferreira LAB, Franco de Moura RC, Eliege de Souza M, et al. Effect of different insoles on postural balance: A systematic review. Journal of Physical Therapy Science. 2013; 25(10):1353-6. doi: 10.1589/ jpts.25.1353

[3] Collings R, Paton J, Chockalingam N, Gorst T, Marsden J. Effects of the site and extent of plantar cutaneous stimulation on dynamic balance and muscle activity while walking. The Foot. 2015; 25(3):159-63. doi: 10.1016/j.foot.2015.05.003

[4] Corbin DM, Hart JM, McKeon PO, Ingersoll CD, Hertel J. The effect of textured insoles on postural control in double and single limb stance. Journal of Sport Rehabilitation. 2007; 16(4):363-72. doi: $10.1123 /$ jsr.16.4.363

[5] Feizolahi F, Azarbayjani MA. [Comparison of static and dynamic balance in amateur male athletes (Persian)]. Journal of Rehabilitation Medicine. 2015; 3(4): 89-98.

[6] Hertel J, Gay MR, Denegar CR. Differences in postural control during single-leg stance among healthy individuals with different foot types. Journal of Athletic Training. 2002; 37(2):129-32. PMCID: PMC164334

[7] Woo MT, Davids K, Liukkonen J, Jaakkola T, Chow JY. Effects of textured compression socks on postural control in physically active elderly individuals. Procedia Engineering. 2014; 72:162-7. doi: 10.1016/j.proeng.2014.06.028

[8] Kavounoudias A, Roll R, Roll J-P. The plantar sole is a "dynamometric map" for human balance control. Neuro Report 1998; 9(14):3247-52. doi: 10.1097/00001756-199810050-00021

[9] Akbari M, Mohammadi M, Saeedi H. [Effects of rigid and soft foot orthoses on dynamic balance in females with flatfoot (Persian)]. Medical Journal of The Islamic Republic of Iran. 2007; 21(2):91-7.

[10] Ali ME, Mohamed MS. [Dynamic postural balance in subjects with and without flat foot (Persian)]. Bulletin of Faculty of Physical Therapy. 2011; 16(1):7-11.

[11] Cobb SC, Tis LL, Johnson BF, Higbie EJ. The effect of forefoot varus on postural stability. Journal of Orthopaedic \& Sports Physical Therapy. 2004; 34(2):79-85. doi: 10.2519/ jospt.2004.34.2.79

[12] Harrison PL, Littlewood C. Relationship between pes planus foot type and postural stability. Indian Journal of Physiotherapy and Occupational Therapy. 2010; 4(3):21-4

[13] Khatatbeh M, Dabayebeh I. Effectiveness of specialized small motor games for the improvement of dynamic balance in flexible flat foot. Jordan Medical Journal. 2012; 46(4):321-30.

[14] Mirahmadi M., Karimi MT, Mostamand J. [Stability analysis of patients with various neurological and musculoskeletal disorders based on linear and nonlinear approaches (Persian)]. Journal of Research in Rehabilitation Sciences. 2013; 9(6):969-77.

[15] Rome K, Brown CL. Randomized clinical trial into the impact of rigid foot orthoses on balance parameters in excessively pronated feet. Clinical Rehabilitation. 2004; 18(6):624-30. doi: 10.1191/0269215504cr767oa

[16] Satvati B, Karimi MT, Tahmasebi Boldaji R, Pool F. [Standing stability evaluation in subjects with flat foot (Persian)] Journal of Research in Rehabilitation Sciences. 2013; 8(8): 1277-84.

[17] Takata Y, Matsuoka S, Okumura N, Iwamoto K, Takahashi $\mathrm{M}$, Uchiyama E. Standing balance on the ground: The influence of flat feet and insoles. Journal of Physical Therapy Science. 2013; 25(12):1519-21. doi: 10.1589/jpts.25.1519

[18] Tsai LC, Yu B, Mercer VS, Gross MT. Comparison of different structural foot types for measures of standing postural control. Journal of Orthopaedic \& Sports Physical Therapy. 2006; 36(12):942-53. doi: 10.2519/jospt.2006.2336

[19] De Morais Barbosa C, Barros Bertolo M, Marques Neto JF, Bellini Coimbra I, Davitt M, de Paiva Magalhaes E. The effect of foot orthoses on balance, foot pain and disability in elderly women with osteoporosis: A randomized clinical trial. Rheumatology. 2012; 52(3):515-22. doi: 10.1093/rheumatology/ kes300

[20] Hatton AL, Dixon J, Rome K, Martin D. Standing on textured surfaces: Effects on standing balance in healthy older adults. Age and Ageing. 2011; 40(3):363-8. doi: 10.1093/ageing/afr026 
[21] Jamali A, Forghany S, Bapirzadeh Kh. [The effect of textured insole on balance in people with functional ankle instability (Persian)]. Journal of Research in Rehabilitation Sciences. 2014; 10(5):619-26.

[22] Hatton AL, Rome K, Dixon J, Martin DJ, McKeon PO. Footwear interventions. Journal of the American Podiatric Medical Association. 2013; 103(6):516-33. doi: 10.7547/1030516

[23] Orth D, Davids K, Wheat J, Seifert L, Liukkonen J, Jaakkola $\mathrm{T}$, et al. The role of textured material in supporting perceptual-motor functions. PLoS ONE. 2013; 8(4):60349. doi: 10.1371/ journal.pone. 0060349

[24] McKeon PO, Stein AJ, Ingersoll CD, Hertel J. Altered plantar-receptor stimulation impairs postural control in those with chronic ankle instability. Journal of Sport Rehabilitation. 2012; 21(1):1-6. doi: 10.1123/jsr.21.1.1

[25] Perry SD, Radtke A, McIlroy WE, Fernie GR, Maki BE. Efficacy and effectiveness of a balance-enhancing insole. The Journals of Gerontology Series A: Biological Sciences and Medical Sciences. 2008; 63(6):595-602. doi: 10.1093/gerona/63.6.595

[26] Aruin AS, Kanekar N. Effect of a textured insole on balance and gait symmetry. Experimental Brain Research. 2013; 231(2):201-8. doi: 10.1007/s00221-013-3685-Z

[27] Palluel E, Nougier V, Olivier I. Do spike insoles enhance postural stability and plantar-surface cutaneous sensitivity in the elderly. Age. 2008; 30(1):53-61. doi: 10.1007/s11357-0089047-2

[28] Waddington G. Football boot insoles and sensitivity to extent of ankle inversion movement. British Journal of Sports Medicine. 2003; 37(2):170-5. doi: 10.1136/bjsm.37.2.170

[29] Redmond AC, Crosbie J, Ouvrier RA. Development and validation of a novel rating system for scoring standing foot posture: The foot posture index. Clinical Biomechanics. 2006; 21(1):89-98. doi: 10.1016/j.clinbiomech.2005.08.002

[30] Preszner-Domjan A, Nagy E, Szíver E, Feher-Kiss A, Horvath $G$, Kranicz J. When does mechanical plantar stimulation promote sensory re-weighing: standing on a firm or compliant surface. European Journal of Applied Physiology. 2011; 112(8):2979-87. doi: 10.1007/s00421-011-2277-5

[31] Steinberg N, Waddington G, Adams R, Karin J, Tirosh O. The effect of textured ballet shoe insoles on ankle proprioception in dancers. Physical Therapy in Sport. 2016; 17:38-44. doi: 10.1016/j.ptsp.2015.04.001 